\title{
Coagulation Efficiency of Okra Seed Extract for Surface Water Treatment
}

\author{
Kumari Anjali Jatav', Sandhya Gawas ${ }^{2}$, Shalu Yadav ${ }^{3}$, Akshita Parmar ${ }^{4}$, Puja Kadam ${ }^{5}$ \\ 1, 2, 3, 4, 5 Mumbai University, Theem college of Engineering, Boisar, Department of Civil Engineering, Mumbai, Maharashtra
}

\begin{abstract}
Conventional drinking water treatments are often inappropriate in developing countries like India, the main reason behind this is high cost for treatment, lack of inappropriate infrastructure or availability of chemicals and also a health problems. The present study aimed to the evaluation of treatment efficiency of natural coagulant i.e. okra seed extract, commonly available in market. The coagulation ability was evaluated by the use of standard jar test experiment involving water sample (obtained from River Surya of Maharashtra) with various coagulant doses. The positive coagulation activity of okra seed extract was measured on the basis of turbidity removal. It was found from the results obtained that okra seed coagulant was effective in removing the turbidity of surface water because turbidity of water sample considered were removed effectively at an optimum dose of $200 \mathrm{mg} / \mathrm{l}$.
\end{abstract}

Keywords: Coagulation, Okra Seed Extract, Jar Test Experiment, Turbidity.

\section{Introduction}

Availability of pure drinking water has become scant now days due to poor land use management. Surface water is being polluted by sewage, industrial water discharge and run off from the land, while ground water is polluted by salt water intrusion and waste dumping site.

The presence of certain contaminants in our water can lead to health issues, including gastrointestinal illness, reproductive problems, and neurological disorders. Infants, young children, pregnant women, the elderly, and immune compromised persons may be especially at risk for becoming ill after drinking contaminated water. For example, elevated levels of lead can cause serious health problems, especially for pregnant women and young children.

This polluted water will have to go through treatment processes before it can be circulated to the consumers for domestic use, including drinking (Anto, 2009). One of the processes of water treatment is coagulation. In water treatment, coagulation occurs when a coagulant is added to water to "destabilize" colloidal suspensions. "Coagulation is one of the cheapest processes for treatment of various organic effluents."

Aluminum sulfate is a chemical compound with the formula $\mathrm{Al}_{2}\left(\mathrm{SO}_{4}\right)_{3}$. It is soluble in water and is mainly used as a flocculating agent in the purification of drinking water and waste water treatment plants, and also in paper manufacturing. Aluminum is regarded as an important poisoning factor in dialysis encephalopathy. Aluminum is one of the factors which might contribute to Alzimer disease .Aluminum reaction with water reduces water $\mathrm{pH}$ and its efficiency in cold water.

The use of locally grown and natural coagulants may result in a more sustainable and economically viable alternative. Many plants have been used to clarify water. Naturally occurring coagulants are usually presumed safe for human health. These include Moringa oleifera, Moringa stenopetala, Vicia faba , Canavalia ensiformis, Bombax,constatum and okra seed have been found to be viable replacement coagulant for chemicals such as aluminum sulphate (alum). The flocculating activities of the fresh stems of mucilage of Gumbo (Hibiscus esculents) and achieved the lowering of turbidity.

Okra (Abelmoschus esculentus) as a natural coagulant. Okra is uncouth in tropical, subtropical and warm temperate regions around the world (National Research Council, 2006). According to the information available in the literature, okra has been found not only to be edible but also used as a coagulant in wastewater treatment.

\section{Materials And Methods}

\subsection{Materials}

The materials used in this study were purchased from nearby vegetable market (Mumbai).The okra seeds were used for preparation of coagulant extract. Hydrochloric acid and sodium hydroxide were used to adjust $\mathrm{pH}$ of stock solution. The preparation of coagulant powders has been elucidated.

\subsection{Okra (lady finger or bhindi)}

Okra (gumbo) is already an important vegetable crop grown in tropical and subtropics parts of the world. The okra seeds are used for the treatment of water sample. For the water treatment, the oil contained in the okra seeds was first extracted, before the okra seeds used. In the range of studied, it is observed that whatever the volume of gumbo mucilage, the turbidity decreases when the $\mathrm{pH}$ increases.

\subsection{Water sample}

The water sample for the testing was collected from the Surya river (Boisar). The collection of water sample was used within the period of 2-3 weeks and stored the water sample at the temperature of about $2^{0} \mathrm{C}$ using refrigerator. Two different samples and volume of 40 liters, each were collected, and the raw characteristics were recorded. 


\section{International Journal of Science and Research (IJSR) \\ ISSN (Online): 2319-7064}

Index Copernicus Value (2013): 6.14 | Impact Factor (2014): 5.611

\subsection{Preparation of coagulants}

Seeds powders and stock solution:

The okra seeds were brought form local market .The seeds were initially washed to remove all impurities in it, they are sun dried for 24 hrs at normal temperature, then grinded the dried seeds using pestle and mortar to obtaining powdered form and sieve to a mesh(500) $\mu$ particles size to remove the large particles size of the seeds. $10 \mathrm{~g}$ of seeds powders was mixed with $1000 \mathrm{ml}$ of distilled water to form $1000 \mathrm{ml}$ of suspension. The suspension was then thoroughly mixed using a clean magnetic stirrer for $5 \mathrm{~min}$ to extract the component. The solution was left untouched for 15 min suspension, then filtered to remove particles and dried the powder left for 6-8 hrs.

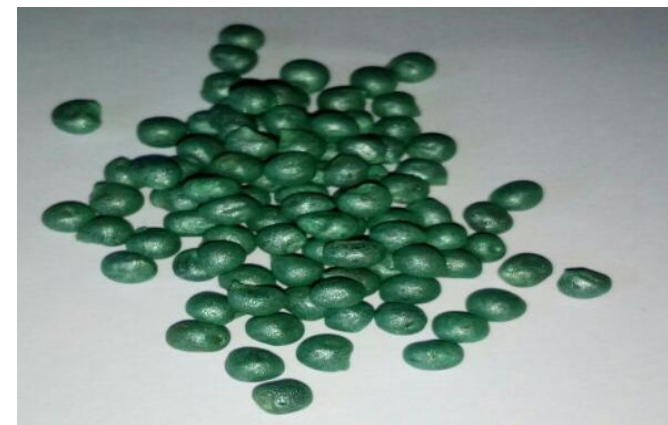

Figure 1: Okra seeds

\subsection{Experimental Work}

Before the treating water sample, their initial parameter was check, especially pH Turbidity, total hardness, total dissolved solids (TDS), temperature and conductivity with the corresponding digital meters. $\mathrm{pH}$ by $\mathrm{pH}$ meter, Turbidity by Turbidity meter, TDS by TDS meter, temperature by Thermometer and conductivity by conductivity meter.

Sedimentation jar test methods were used to determine the coagulation properties of the derived okra coagulant. 6 beakers were used simultaneously with various doses of coagulants with the same quantity of sample. The jar test was conducted using $500 \mathrm{ml}$ of each of the surface water samples. In these samples some amount of coagulant (Okra seeds extract) was added to the sample, and subjected to jar test mixing at $120 \mathrm{rpm}$ for 3min and later slow mixing at $20 \mathrm{rpm}$ for $20 \mathrm{~min}$. Thereafter, switched off the stirrer and allowed the flocks to settle without disturbing the beakers for $30 \mathrm{~min}$. The samples for residual turbidity mearsurement were withdrawn using a pipette from a height of $5 \mathrm{~cm}$ below the surface of each beaker, and the residual turbidity was measured for each sample of beaker. Effect of dose of okra coagulants on removal of turbidity also studied.

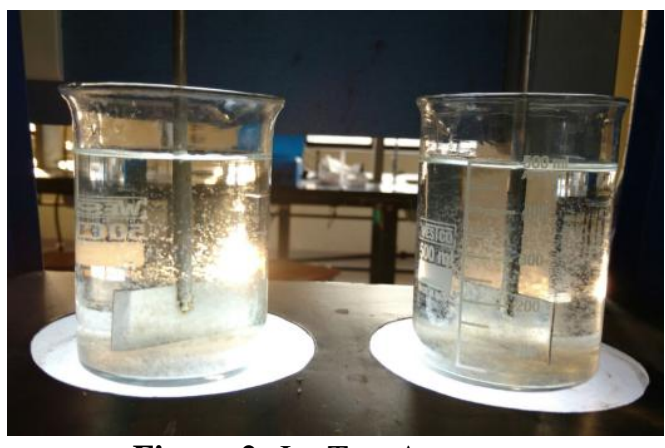

Figure 2: Jar Test Apparatus

\section{Results and Discussion}

\subsection{Results}

Table 1: Raw water sample parameters

\begin{tabular}{|c|c|c|}
\hline $\begin{array}{c}\text { Sr. } \\
\text { No }\end{array}$ & Parameters & $\begin{array}{c}\text { Raw Water } \\
\text { Characteristics }\end{array}$ \\
\hline 1 & Turbidity (NTU) & 17.0 \\
\hline 2 & $\mathrm{pH}$ & 8.4 \\
\hline 3 & Hardness (mg/l) & 230 \\
\hline 4 & Alkalinity(mg/l) & 108.15 \\
\hline 5 & Total dissolved solid(mg/l) & 320 \\
\hline 6 & Total suspended solid(mg/l) & 280 \\
\hline 7 & Total solid(mg/l) & 760 \\
\hline 8 & Chloride (mg/l) & 32.51 \\
\hline
\end{tabular}

Table 2: Results of Alum treatment

\begin{tabular}{|c|c|c|c|c|c|}
\hline $\begin{array}{c}\text { Sr. } \\
\text { No }\end{array}$ & Parameter & $10 \mathrm{mg} / \mathrm{l}$ & $20 \mathrm{mg} / \mathrm{l}$ & $30 \mathrm{mg} / \mathrm{l}$ & $40 \mathrm{mg} / \mathrm{l}$ \\
\hline 1 & Turbidity (NTU) & 4.5 & 4.26 & 3.8 & 3.92 \\
\hline 2 & $\begin{array}{c}\text { Total Dissolved Solids } \\
(\mathrm{mg} / \mathrm{l})\end{array}$ & 200 & 220 & 212 & 217 \\
\hline 3 & Suspended Solids (mg/l) & 200 & 205 & 180 & 194 \\
\hline 4 & Total Solids (mg/l) & 430 & 415 & 405 & 413 \\
\hline 5 & $\mathrm{pH}$ & 7.48 & 7.45 & 7.4 & 7.41 \\
\hline
\end{tabular}

Table 3: Results of Okra Seeds

\begin{tabular}{|c|c|c|c|c|}
\hline $\begin{array}{c}\text { Sr. } \\
\text { No }\end{array}$ & Parameter & $150 \mathrm{mg} / \mathrm{l}$ & $200 \mathrm{mg} / \mathrm{l}$ & $250 \mathrm{mg} / \mathrm{l}$ \\
\hline 1 & Turbidity (NTU) & 5.61 & 4.52 & 4.67 \\
\hline 2 & Total Dissolved Solids (mg/l) & 270 & 228 & 242 \\
\hline 3 & Suspended Solids (mg/l) & 240 & 223 & 230 \\
\hline 4 & Total Solids (mg/l) & 518 & 455 & 470 \\
\hline 5 & $\mathrm{pH}$ & 7.67 & 7.42 & 7.56 \\
\hline
\end{tabular}

\subsection{Discussions}

A graph of turbidity (NTU) against dosage number

\section{Turbidity removal by Alum}

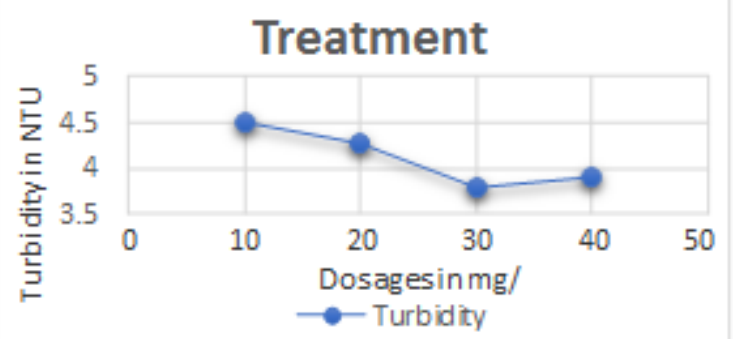

Figure 3: A graph that shows relationship between the alum Turbidity (NTU) and Dosages (mg/l) 


\section{International Journal of Science and Research (IJSR) \\ ISSN (Online): 2319-7064}

Index Copernicus Value (2013): 6.14 | Impact Factor (2014): 5.611

A graph of Turbidity (NTU) against dosage number

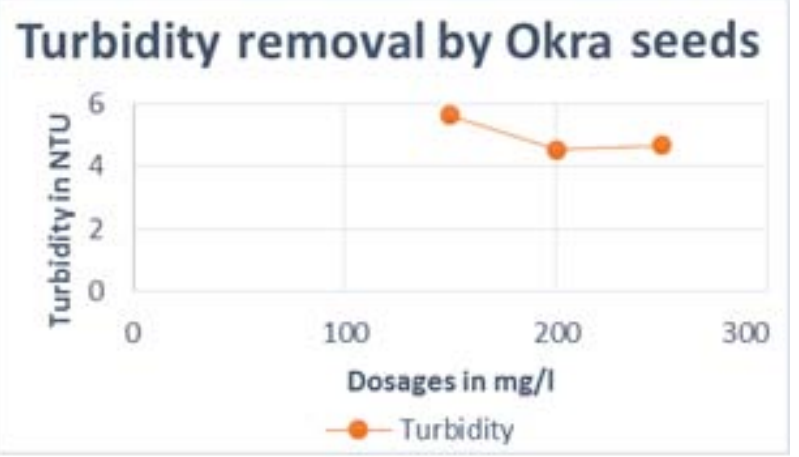

Figure 4: A graph that shows relationship between the okra seeds and Dosages (mg/l)

The turbidity value was observed to be 17 (NTU) in the raw water sample, which is above both national and international standards of drinking water quality. After the treatment with various coagulants, the turbidity decrease to 4.52(NTU) on Okra seeds with optimum dosages of $200 \mathrm{mg} / \mathrm{l}$ respectively, while alum is 3.8 with coagulant dosage of $30 \mathrm{mg} / \mathrm{l}$. The highest removal efficiency of okra is $73.41 \%$ while that of alum is $77.64 \%$.

\section{Summary and Conclusion}

The increase in water demand for domestic uses, caused by population growth and by the rising standard of living, together with progressive environmental pollution problems have led to over utilization of renewable drinking water sources and the diminution of water quality. Many countries and, especially large cities are facing with a water scarcity problem. In the developing country treatment plants are very expensive, the ability to pay for services is minimal and skills as well as technology are scant. Therefore, locally available materials can be utilized towards achieving sustainable safe water supply. The study was conducted to okra seeds as new source of bioremediation for the surface water treatment. A comparative study was made for different okra seeds, and alum dosages and effect on turbidity, TDS, TS, SS \& pH was calculated.

It was thus obtained that the maximum removal efficiency of alum and okra seeds were $77.64 \%$ and $73.41 \%$ for $200 \mathrm{mg} / \mathrm{l}$ and $30 \mathrm{mg} / \mathrm{l}$ respectively. While the sludge obtained by treatment alum was higher than that of okra seeds. It can be thus suggested that we can use locally available material okra seeds to treat low turbid waste water which is environmental friendly as well as cost effective. In short natural coagulants are sustainable and economical way of water treatment process.

\section{References}

[1] Lukman Aliyu, Mukhtar L.W, S.I Abba," Assessment Of Coagulation Efficiency of Natural Coagulants (Moringa Oliefeera, Okra) And Alum, for Yamuna Water treatment." $\quad 2^{\text {nd }}$ International conference on Science,Technology and Management. (27 September 2015)
[2] Yusuf olabode RAJI, Lawl ABUBAKAR, Saidat Olanipekun GIWA, Abdulwahab GIWA,"Assessment of Coagulation Efficiency of Okra Seed Extract for Surface Water Treatment" International Journal of Scientific and Engineering Research, Volume 6, Issue 2, ISSN 22295518, February-2015.

[3] Sunita Singh Thakur and Sonal Choube," Assesment of Coagulation Efficiency of Moringa Olifera and Okra for Treatment of Turbid Water." Archieves of Applied Science Research, 2014, 6 (2):24-30, ISSN 0975-508X

[4] Renuka A. Binayke, M.V. Jadhav, "Assesment of Purification of Water by Using Natural Hurbs." Lokavishkar International E-Journal, ISSN 2277-727X, Volume-I, Issue-IV, (Oct-Nov-Dec 2012).

[5] Anto, M.G. (2009). Seed as a natural coagulant for potential application in water turbidity removal, McGraw Hill, New York.

[6] Bratby, J. (2006). Coagulants in water and wastewater treatment. London: IWA Publishers, London,

[7] IRC 1994 International water and Sanitation Centre WHO Collabration, water, water news letter development in water, Sanitation and Environment. No. 27, September 1994

[8] Schertenlieb, R. (1992). The water Supply situation in developing countries. Roughing filters for water treatment. Workshop in Zurich 25-27 June 1992.

[9] WHO. (1992). Guidelines for drinking-water quality, Volume 1, Recommendation, Second edition. World Health Organisation, Geneva.

[10]A.G Bhole, "Performance studies of a few natural coagulants" Journal of Indian Water Works Assoc 1990, pp..81-84. 